\title{
Knowledge Integration in Distributed Product Development
}

\author{
Jonas Rundquist ${ }^{1}$ \\ ${ }^{1}$ Halmstad University, School of Business and Engineering, Halmstad, Sweden \\ Joru@hh.se
}

\begin{abstract}
Research has indicated that small and medium sized firms (SMEs) play an important role in the growth of the economy. However, in order to be able to compete at an international level, most SMEs are bound to work in alliances in order to gather enough knowledge and resources for product and technology development or to be able to penetrate a larger market. Alliances can be formed with different types of actors (i.e., suppliers, customers, agents, universities, consultancies); in the alliance, information and knowledge are gathered and created. Information is defined as "knowledge that can be transmitted without loss of integrity," which includes facts, axiomatic propositions, and symbols. This knowledge can be categorized as domain-specific, procedural, or general. In the present study, a case approach is used to investigate how different types of information and knowledge generated through distributed product development are integrated into the firm, what methods are used, and some conclusions on what methods are more successful for each type of information or knowledge. Results indicate a very high representation of formal information sharing (document exchange) even if there is a high degree of agreement among the respondents that personal meetings and continuous information sharing would be better if they had a system for this. Therefore, the conclusions should lead to systems that address the above problems.
\end{abstract}

\section{INTRODUCTION}

Research has indicated that small and medium sized firms (SMEs) play an important role for innovation and the growth of the economy [1]. However, in order to compete in a global market, most SMEs are bound to work in alliances (distributed organizations) to gather enough knowledge to conduct complex tasks such as new product development (NPD) [2]. To maximize the benefits of knowledge developed through these alliances, the issue of integrating knowledge gained through shared NPD projects is important.

There is a growing stream of literature investigating knowledge integration and its importance for new product development performance [3, 4]. This literature focuses on knowledge integration either as a unit or as a process typically including a number of phases (e.g., acquisition, sharing, using). Few studies consider the type of external knowledge sourced from outside the organization.

Knowledge integration has been studied as codified knowledge or information with a focus on IT tools to support knowledge integration [5]. In this study, knowledge is considered as including both codified (information) and tacit knowledge. Some studies have looked beyond the IT tools and found that knowledge integration requires collaboration among alliance partners. Otherwise it might just be knowledge transfer [6]. This study explores the degree of involvement between the source firm and the recipient firm, and specifically whether the type of knowledge affects the need for involvement between the firms.

The contribution of the study is a framework combining three types of knowledge (domain-specific, procedural, and general) with the degree of involvement between individuals (impersonal interaction, personal interaction, and collaboration). Integrative effectiveness is investigated in relation to the degree of involvement from individuals in the knowledge integration.

\section{DISTRIBUTED PRODUCT DEVELOPMENT}

According to the Aberdeen Group's Global Product Design Benchmark Report [7], today's products are increasingly brought to market by cross-enterprise teams that span multiple geographic borders. This is often called distributed product development. Distributed product development is defined by the 
Product and Development Management Association (PDMA) as the separation and optimization of activities performed during a single product development process (i.e., product ideation, development, and launch) across multiple geographic locations [8]. These locations may be within a single corporate entity, within subsidiaries, or involve the use of third parties.

According to PDMA's definition, all the cases of the study involve third parties. When small and medium sized firms gather resources by using distributed NPD, the main reason is to find knowledge and resources that could not be gathered within the organization.

Alliances involving the use of third parties can be formed with different types of actors (i.e.; suppliers, customers, agents, universities, consultancies); and in these alliances, knowledge is gathered and created. Inter-firm alliances require at least two partners, though a growing number of cooperations involve more than two partners. The NPD projects of this study are all conducted in an alliance context as described earlier. This means that the projects have been joint efforts with potential profits shared mutually. Each partner is definitely able to make autonomous decisions as they are equally strong and participate in the alliance only due to their mutual interests.

\section{THEORETICAL FRAMEWORK}

In this section, important terms around knowledge integration effectiveness are defined and two propositions developed. Knowledge integration effectiveness will be examined according to codification and personalization, and classified into three levels of involvement. The connection between knowledge integration effectiveness and level of involvement will then be examined in combination with the type of knowledge, moving from the most project-specific to the most general knowledge.

\subsection{A measure of integrative effectiveness}

If INTEGRATIVE effectiveness IS DEFINED AS HOW EFFECTIVELY ORGANIZATIONAL MEMBERS CAN ACQUIRE, CONVERT AND APPLY KNOWLEDGE PROVIDED BY OTHER MEMBERS OF THE COLLABORATION, these three dimensions shape the measure of integrative effectiveness. Knowledge is sent between individuals with media or a method. Effectiveness depends on the individuals' capability to send and acquire knowledge, and of the effectiveness of the media or method used in a specific situation.

To complete integration, the knowledge must be acquired, converted and applied. Therefore, integrative effectiveness is an assessment of the value that the integrated knowledge provides to the organization. In order to provide value it must be acquired and converted, which is the proper measure of integrative effectiveness. Existence of integration success factors described by Grant [13] as common language, frequent interaction, and a codified structure, are not a measure of integrative effectiveness. An integration effectiveness measure must be based on the use and the value of knowledge integrated; that is, the quantity of knowledge, the quality of knowledge, and the actual use of the knowledge.

Even if the focus is on the media or method used to transmit the knowledge, the nature of the method affects the individuals' capability to acquire and convert knowledge. For example, the method of integration will affect the message sent and acquired, but also the individuals' ability and motivation to acquire, convert and apply the knowledge. In order to measure integrative effectiveness, integrated knowledge is identified in different projects in the three case firms. It can be use of knowledge on a specific technology (e.g., steam or transformers), knowledge about project management (e.g., software or special meeting techniques), or knowledge about general topics (e.g., trends on use of cars in China).

In the study, knowledge integration processes have been identified, and the extent of acquiring and converting of the knowledge rated. Some examples are presented with the results.

\subsection{Integrative effectiveness and the level of involvement}

The acquisition of technological knowledge does not translate automatically into strong competitive market positions or high performance [9]. It is the integration that helps organizations to develop shared learning and accumulate knowledge over time [10]. Integration enables the firm to internalize the knowledge gained from its distributed work. In order to establish effective processes for product development, it is important to share knowledge between functions. In a distributed context, that will mean sharing knowledge between organizationally and geographically divided units. This also means that the individuals may not only work in different departments, but also in different organizations [11]. 
To achieve knowledge integration, personal and impersonal interaction should take place [12]. Personal interaction could be participation in meetings or phone conversations, while impersonal interaction could be exchanging of emails or reports. A third method for integration is direct collaboration [12]. Personal and impersonal interactions, as well as collaboration, are important for the integration of knowledge. This puts focus on how involved the individuals are; a degree of closeness.

According to Grant [13], integrative effectiveness is a function of common knowledge among organizational members, frequency and variability of common activities, and a supportive structure (e.g., a modular structure). This suggests that the most efficient integration of knowledge should be with co-located individuals who share the same physical room. They are more likely to develop a common language of discourse and frequently interact with each other. In distributed product development, it is more likely to find lower degrees of involvement as occasional physical meetings, but even more likely to communicate via phone or email. These are examples of different degrees of involvement and lead to proposition 1 .

Proposition 1: Knowledge integration effectiveness will increase if methods of knowledge integration with a higher degree of involvement between individuals are used.

\subsection{Type of knowledge as a moderating factor}

Many efforts have been made to describe and categorize knowledge from different traditions and perspectives $[14,15,16]$. An often recurring distinction is between general knowledge and specific knowledge [13, 17]. Specific knowledge is context-specific (e.g., knowledge about a technology or a market), while general knowledge is applicable in different contexts and often publicly available. For example, demographic statistical data and data from public patent databases are considered general knowledge. Edvinsson and Sullivan [16] discuss the distinction between product knowledge and procedural knowledge, where product knowledge is codified and revealed if the product is sold. Meanwhile, procedural knowledge is knowledge of business processes. Zack [17] adds to the concept of procedural knowledge by showing that procedural knowledge can be both codified (e.g., a description on how to bake cookies in a bakery), or not codified (e.g., the professional feeling of the baker). General knowledge is, according to Zack [17], not meaningful to codify as it is public and changes continuously.

In this study, the categories from Ullman [18] are used as they merge these two logics into three categories. The first category, domain-specific knowledge, is knowledge of "...the form or function of an individual object or class of objects" [18: p50]. This means that domain-specific knowledge includes knowledge acquired as the result of previous or ongoing product development projects [19, 20]. Domain-specific knowledge can be of a technological nature, but also include other areas of knowledge directly connected to the result of the project [21].

A second category of knowledge is procedural knowledge. This is the know-how of the NPD process [22] or the collaborating process [23]. Procedural knowledge refers to "[t]he knowledge of what to do next" [18] in the entire NPD process that typically consists of different stages. Procedural knowledge supports the process of gaining new knowledge and new results in future projects. Procedural knowledge addresses both firm-internal and external aspects of NPD activities.

A third category is general knowledge. This can be knowledge about market, technology or societal situations (peripheral in the present NPD process) that could be useful in future product development projects. Such general knowledge is thus applicable across both organizational procedures and specific technological domains [18].

Ramesh and Tiwana [20] elaborated that domain-specific knowledge can be integrated with less involving methods. Following the earlier reasoning of Zack [17], procedural knowledge can be codified and integrated with less involving methods, but also be of a non-codifiable nature. In this case, more involving methods would be needed for efficient integration. General knowledge is, according to Zack [17], not meaningful to codify and would thereby need a higher degree of involvement to be efficiently integrated. Therefore the following proposition is made.

Proposition 2: P1 is stronger for general knowledge than for procedural knowledge, and weakest for domain-specific knowledge. 


\section{METHOD}

If the limits of a phenomenon to be studied are not apparent at the beginning of investigation, the best option to validate the research will be a case study [24]. The same is valid when control and/or experimental manipulation are not possible to use, due to the complexity of context and/or lack of knowledge about independent and dependent variables [25]. Knowledge integration in a distributed organization is a very complex phenomenon that needs to be studied in its context. In the present project, a case study approach is used to investigate how different types of knowledge, generated in a distributed product development project, are integrated in the individual firm.

The firms are medium sized (between 227-357 employees) and situated in the manufacturing sector (see table 1 for description). All three firms also have an extensive R\&D operation in-house, which is important for the study.

Table 1. Summary of the Firms in the Case Study, Figures from 2010

\begin{tabular}{|c|c|c|c|c|}
\hline & Industry & Turnover in & Millions of Euros & Number of Employees $\quad$ Description \\
\hline$\overline{\mathrm{A}}$ & $\begin{array}{l}\text { Medical } \\
\text { Equipment 1* }\end{array}$ & 30 & 227 & $\begin{array}{l}\text { Firm A develops, manufactures, and markets small units for medical } \\
\text { analysis targeting hospitals and clinics. Most development is carried out } \\
\text { in Sweden in collaboration with research hospitals as well as } \\
\text { mechanical suppliers, but also in Asia and in the US. }\end{array}$ \\
\hline $\mathrm{B}$ & $\begin{array}{l}\text { Office } \\
\text { Appliances } \\
\text { Materials }\end{array}$ & 98 & 356 & $\begin{array}{l}\text { Firm B is one of the world's leading companies within its industry with } \\
\text { sales in more than } 140 \text { countries. The firm owns research and } \\
\text { development facilities in Sweden and collaborates with external } \\
\text { suppliers of NPD services in local areas and abroad. }\end{array}$ \\
\hline$\overline{\mathrm{C}}$ & $\begin{array}{l}\text { Medical } \\
\text { Equipment }\end{array}$ & 65 & 357 & $\begin{array}{l}\text { Firm C is the world's leading provider of special solutions for the } \\
\text { healthcare sector. R\&D is mostly conducted within its subsidiaries in } \\
\text { Northern Europe with a focus on Scandinavia. }\end{array}$ \\
\hline
\end{tabular}

$1 *$ Firm bought by a multinational company in 2008.

The three firms in the study have participated in different research projects since 2001. This is important, as it gives easy access to the firms, their employees and documents. The researchers also have good knowledge about operations due to the long-time cooperation. In this specific study, however, the collection of empirical material adds 15 unstructured interviews with employees in the three firms.

All the respondents are deeply involved in product development in an alliance context. The respondents in the firms were R\&D managers, HR managers, production managers and project managers or members of ongoing product development projects in an alliance context. The interviews were conducted during autumn 2010 and were used for finding operational examples of knowledge integration and to assess effectiveness in knowledge integration using the model from table 2.

For within-case analysis, the model in table 2 was used. The categorization had the purpose of finding patterns in the knowledge integration methods of the firm. These patterns include strategic statements regarding, for example, which methods and practices were suggested from a managerial level, but also how the knowledge integration work was actually conducted. In the cross-case analysis, general conclusions of effectiveness in the knowledge integration work were drawn. 
Table 2. Examples of Operationalization of the Dimensions Studied in the Cases

\begin{tabular}{|c|c|c|}
\hline $\begin{array}{l}\text { Knowledge } \\
\text { integration } \\
\text { effectiveness }\end{array}$ & Consists (for example) of item & Examples of observations in cases \\
\hline \multirow{3}{*}{$\begin{array}{l}\text { Knowledge } \\
\text { acquisition } \\
\text { effectiveness }\end{array}$} & The firm acquires knowledge from the collaboration. & $\begin{array}{l}\text { Knowledge is acquired in reports or protocols } \\
\text { distributed between organizations. }\end{array}$ \\
\hline & $\begin{array}{l}\text { Knowledge is exchanged between individuals in } \\
\text { different firms in the collaboration. }\end{array}$ & $\begin{array}{l}\text { Knowledge is acquired in meetings between individuals } \\
\text { from different firms. }\end{array}$ \\
\hline & $\begin{array}{l}\text { The firm uses feedback from projects to improve } \\
\text { subsequent projects. }\end{array}$ & $\begin{array}{l}\text { Post project evaluation is a frequent tool used internally } \\
\text { in the firm }\end{array}$ \\
\hline \multirow{3}{*}{$\begin{array}{l}\text { Knowledge } \\
\text { conversion } \\
\text { effectiveness }\end{array}$} & The firm converts knowledge into the NPD process. & $\begin{array}{l}\text { Reports or protocols are analysed within the NPD } \\
\text { organization }\end{array}$ \\
\hline & $\begin{array}{l}\text { The firm distributes knowledge throughout the } \\
\text { collaboration. }\end{array}$ & $\begin{array}{l}\text { Meetings intra-firm participants, sorting and storing } \\
\text { knowledge are used. }\end{array}$ \\
\hline & The firm replaces outdated knowledge. & $\begin{array}{l}\text { The firm has formal routines for evaluating new } \\
\text { knowledge reported from projects. }\end{array}$ \\
\hline \multirow{5}{*}{$\begin{array}{l}\text { Knowledge } \\
\text { application } \\
\text { effectiveness }\end{array}$} & $\begin{array}{l}\text { The firm matches sources of knowledge to } \\
\text { problems and challenges. }\end{array}$ & $\begin{array}{l}\text { Meetings with cross functional (e.g., marketing or } \\
\text { R\&D) participants are used where needs meet }\end{array}$ \\
\hline & & possibilities. \\
\hline & Knowledge is accessible to those who need it. & $\begin{array}{l}\text { Arenas and meeting points to find individuals with } \\
\text { specific knowledge are present. }\end{array}$ \\
\hline & The firm learns from mistakes in previous projects. & $\begin{array}{l}\text { Results from post project evaluation are formally used } \\
\text { in the firm's project models. }\end{array}$ \\
\hline & $\begin{array}{l}\text { The firm takes advantage of new knowledge } \\
\text { produced in the collaboration. }\end{array}$ & $\begin{array}{l}\text { Workshops where new knowledge is applied are used } \\
\text { after finalizing a project. }\end{array}$ \\
\hline
\end{tabular}

\section{RESULTS}

The interviews with management and project members in the three firms indicated that there is a high awareness about the concepts of the study as well as an understanding of the phenomena and the terms used in the study. Discussions around terminology and knowledge integration in general created good construct validity. That is, the terms of the framework are understood and interpreted in a similar way by all respondents and by the interviewer.

\subsection{Effects from degree of involvement at knowledge integration}

All three firms in the study currently place a major emphasis on impersonal methods for achieving knowledge integration. A common pattern is that the projects start with a meeting between R\&D managers in the alliance to discuss collective goals and mutual understanding. However, this meeting culture is not spread down to the project members, who rarely meet. During the project, email and exchange of reports are the dominating methods for knowledge sharing, while the managers meet again two or three times at the end of the projects.

Firm A has as a policy that all project members shall meet in the beginning of a project. They also used this policy earlier, but R\&D managers explained that longer geographical distances have made it more difficult today. New suppliers in China have made travel costs expensive, while new communications technology has made it easier to justify fewer physical meetings. However, in this case, the longer geographical distance also leads to a greater cultural distance, which would rather justify more physical meetings to avoid misunderstandings. The R\&D manager of the firm pointed out that manufacturability of the products developed in collaboration has decreased as knowledge about the partners' plants decreased with distance.

Firm B is the one with the most involving level of collaboration. The obvious explanation is that the partners in the alliance are geographically closer. The managers meet the partners in the beginning of the project, during the project, and after the project. Management also claims that project members are encouraged to meet partners according to their own need. Project members confirmed that there is a lot of discussion with the partner firms regarding project methodology and other types of procedural knowledge.

Firm $\mathrm{C}$ has been under economic pressure for a few years. Today, even though there is an awareness 
of the importance of involving methods of collaboration, there is no money to apply it completely. Economic pressure has led to a lower organizational self-esteem, which makes it hard for project members to communicate. Management shows in the quality handbook how communication shall be handled with impersonal methods, but do not motivate project members to share knowledge types that are not described in the handbook.

In firm $\mathrm{A}$, the larger distance and more less-involving methods of knowledge exchange has decreased knowledge integration. In firm B, a high level of individual involvement supports a high level of knowledge integration effectiveness. In firm $\mathrm{C}$, the focus on impersonal knowledge exchange has led to lower knowledge integration effectiveness. The three cases support proposition 1, stating that knowledge integration will be more efficient when more-involving methods are used.

\subsection{Integration of knowledge with different specificity}

All three firms have a focus on integration of domain-specific knowledge. In product development projects, this means that there are specific routines for how to convert and apply technological knowledge about the product or the key technologies in the product itself. Example of this would include: the function of the product, how to efficiently produce the product, and deeper knowledge of the key technologies used in the product. Two of the firms have some integration of procedural knowledge as post project evaluation (PPE) applied in the continuous improvement of their project management model. However, it was more difficult than expected to find examples of integration of general knowledge.

Firm A has a well-developed system for integrating domain-specific knowledge. The basic idea of EDI (electronic data interchange) has been to avoid redundant recording work and thus to ensure a seamless data exchange. They do not refer to a quality standard, but have a strong culture and structure to support knowledge sharing of domain-specific knowledge. For example, a project management platform presents a checklist for how meetings, reports, and technical protocols shall be stored and shared. The domain-specific knowledge fits well into the structure of the platform. The platform is also used for geographically closer partners, and has led to a stronger emphasis on sharing the appropriate documents.

Firm B, with an alliance in a close distance and a primary focus on collaboration, seems to have a good integration of domain-specific as well as procedural knowledge. The procedural knowledge is, in this case not only developed as PPE, but also in informal intra-firm meetings during the project aiming to improve collaboration processes. Even though Firm B has a much less formalized monitoring system for projects, they seem to have a greater mutual understanding and shared vision than the other firms.

Firm $\mathrm{C}$ has a very strong focus on integration of domain-specific knowledge. Consistent with the findings from Firm A, there are routines for gathering and sharing technological specifications and reports. Two years ago, Firm $\mathrm{C}$ had no integration of procedural knowledge; but during the study they increased their interest in post project evaluation and learned to carry out PPE workshops through knowledge spill-over from Firm A. An initial workshop was carried out in the fall of 2007. The tools and processes for PPE have been integrated during several intra-firm meetings where both firms developed knowledge on PPE. "These meetings have been valuable as a catalyst for increased project effectiveness, especially regarding the monitoring of resource use," according to firm C's CEO.

Firm A has a working system for impersonal knowledge sharing, but also needs personal methods in order to integrate procedural knowledge. Firm B with collaborative methods also integrates procedural knowledge and even general knowledge. Firm $\mathrm{C}$ has increased their effectiveness in integrating procedural knowledge by introducing more involving methods. Material regarding general knowledge is scarcer than domain-specific and procedural knowledge. The three cases support proposition 2, stating that methods involving individuals from the same or different firms, affect knowledge integration effectiveness between these individuals the more less-specific knowledge is in focus.

\section{CONCLUSIONS}

These cases represented in the empirical study have supported the two propositions that: 1) moreinvolving methods for knowledge integration increases knowledge integration effectiveness, and that 2) this is more obvious the less specific knowledge is the object of integration. In Fig. 2, knowledge integration effectiveness is analyzed and indicated in the framework. The term "High" refers to high knowledge integration effectiveness, meaning that knowledge of this type can be efficiently acquired, converted and applied with the specified degree of involvement. 
Table 1. Results from the Study Summarized

\begin{tabular}{llll}
$\begin{array}{l}\text { A Framework for studying integration } \\
\text { of knowledge }\end{array}$ & Collaboration & Personal Interaction & Impersonal Interaction \\
\hline Domain-Specific & Less established & Moderately established & $\begin{array}{l}\text { Well established, works } \\
\text { Knowledge } \\
\text { involving methods }\end{array}$ \\
\hline Procedural Knowledge & $\begin{array}{l}\text { Less established, would } \\
\text { contribute to increased } \\
\text { involvement }\end{array}$ & Moderately established & Moderately established \\
\hline General Knowledge & $\begin{array}{l}\text { Less established, would } \\
\text { contribute to increased } \\
\text { involvement }\end{array}$ & Less established & Less established \\
& & & \\
\hline
\end{tabular}

\section{DISCUSSION}

The first finding is that high involvement increases knowledge integration effectiveness. This finding is consistent with findings from other recent research. For example, Newell et al [26] investigated collaboration and concluded that "strong social capital" is important for knowledge integration. Social capital could be gained by closer collaboration and is a concept close to trust. This is also supported by Enberg et al [27], who stresses the importance of learning processes over time and interaction between project members adapted to the context of a specific project.

Akgün et al [28] investigated the effects of using a transactive memory system (TMS) in a distributed project development project. TMS is an example of how software can be used for both personal and impersonal interaction. In their quantitative study, they concluded that this type of software supported knowledge integration. Software is normally connected with lower degrees of involvement and information processing; but in order to get to a higher level of involvement in distributed projects, especially over long distances, TMS software could be a tool to communicate knowledge.

With a focus on domain-specific knowledge, Vachon and Klassen [29] concluded that collaboration increased knowledge integration in a supply chain environment. The domain-specific knowledge in the study is based on a green supply chain. The study shows indications that the integration of the domainspecific knowledge on environmental technology, as well as, the procedural knowledge on effectiveness in a supply chain is supported by collaboration.

Knowledge generated in a product development project has two different values. First, it generates a product that can be commercialized in the market and generate profit. Second, it adds to the firm's collective knowledge base and can be used in future NPD projects. In order to achieve maximum benefit from investments made in distributed product development, the firm needs to integrate knowledge generated. Knowledge that is not integrated into the firm's collective knowledge capital is not made useful in future product development projects. The decision to invest in knowledge integration is a strategic decision. To do like Firm A and not invest in structures for integrating knowledge means that, in the future, the firm depends on the alliance in order to access the same knowledge. It also means that the firm is not able to communicate around the knowledge or to develop further knowledge in the same field. Firm $\mathrm{C}$ suffers the same disadvantages; however, Firm $\mathrm{C}$ chose not to invest in cultures for integrating knowledge.

\subsection{Contributions and outlook}

The study has contributed to the field of knowledge integration showing the importance of collaboration for effectiveness. Many previous studies focusing on IT as a knowledge enabler have not taken the collaborative aspect under consideration. Previous studies [6] have shown the importance of collaboration to achieve an effective integration between multi-national companies. The present study shows the importance of collaboration also when medium sized firms, working both locally and crossnationally, are involved. It also shows the importance of working both with strategy and firm culture to achieve efficient knowledge integration. Resources invested in a collaborative culture may be seen as a cost in the short run, but can create considerable advantages in the longer run.

A second contribution is the tested categorization of knowledge as domain-specific, procedural and general knowledge. Results have indicated that collaboration is differently important depending on 
what type of knowledge shall be integrated. Domain-specific knowledge seams to need less-involving integration methods, while general knowledge needs more-involving methods of knowledge integration to be efficient.

A third contribution is the methodological approach implementing the framework with practitioners in three firms. This showed that the categorization had a practical relevance, as it is understandable and easy to operationalize in the organization. The long-time work with the firms has contributed to a deeper understanding for the researcher, but also transfers practical support for the firms.

\subsection{Managerial implications}

This article provides some guidance for project members and managers involved in distributed product development projects. It is important to note that managing knowledge in alliances is an important problem and that the main challenge is primarily related to degree of involvement. Firms in alliances need to better understand that not only the results of the project, but also the procedural knowledge of handling the co-operation between firms in an alliance are important to integrate. This integration can be nurtured both with culture (motivation or informality) as structures (methods or organization charts).

The terminology for categorizing types of knowledge and involvement level may be useful to practitioners describing a set of idealized types and examples, as well as correlation between the two sets of categories. Increased awareness of the terminology along with the correlations may assist managers to appropriately initiate actions to nurture structures and culture for knowledge integration.

More generally, managers have the ability to enhance knowledge integration effectiveness through deploying their human capital, turning "knowledge into action" [30]. Managers should allocate their resources carefully because it can show that an investment in collaboration can increase the involvement considerably, creating profits in the longer perspective. Increased collaboration, we can assume, leads to better knowledge integration, which in turn could lead to better use of the knowledge created in the project.

\section{REFERENCES}

[1] Ács, Z. \& Audretsch, D. (2005) Handbook of entrepreneurship research: an interdisciplinary survey and introduction. Kluwer Academic. Boston Mass.

[2] Grant, R. and Baden-Fuller, C. (2004) A Knowledge Accessing Theory of Strategic Alliances. Journal of Management Studies 41(1) 61-84.

[3] Murray, J.Y. \& Chao, M. (2005) A cross-team framework of international knowledge acquisition on new product development capabilities and new product performance. Journal of International Marketing 13: 54-78.

[4] Verona, G. (1999) A resource-based view of product development. Academy of Management Review 24(1) 132-142.

[5] Chang, W-C. \& Li, S-T. (2007) Fostering knowledge management deployment in R\&D workspaces: a five-stage approach. R\&D Management 37 (5), 479-493.

[6] Subramaniam, M. (2006) Integrating cross-border knowledge for transnational new product development. Journal of Product Innovation Management 23(6) 541-555.

[7] Brown, J. (2005) Aberdeen Group: Global Product Design Benchmark Report. < Last accessed Jan 2014, http://www.aberdeen.com/summary/report/benchmark/RA GlobalProduct JmB 2460.asp >

[8] Kahn, K., Castellion, G. \&Griffin, A. (2005) The PDMA Handbook of New Product Development. Wiley Boston MA.

[9] McGrath, M.; McMillan I. \& Venkataraman, S. (1995) Defining and Developing Competence: A Strategic Process Paradigm, Strategic Management Journal 16 (4) : 251-275.

[10] Teece, D.; Pisano, G. \& Shuen, A. (1997) Dynamic Capabilities and Strategic Management, Strategic Management Journal 18(7) 509-533.

[11] Moenaert, R. \& Souder, W. (1990) An information transfer model for integrating marketing and R\&D personnel in new product development. Journal of Product Innovation Management 7 (2) 91-107. 
[12] Kahn, K. (1996) Interdepartmental integration: A definition with implications for product development performance. Journal of Product Innovation Management 13(2) 137-151.

[13] Grant, R. (1996) Prospering in Dynamically-competitive Environments: Organizational Capability as Knowledge Integration. Organization Science 7(4) 375- 387.

[14] Polanyi, M. (1983) The Tacit Dimension. MA, Magnolia, Peter Smith.

[15] Wiig, K.M. (1995) Knowledge Management foundations - thinking about thinking - how people and organizations create, represent, and use knowledge. Schema Press. Arlington, Texas.

[16] Edvinsson, L. and Sullivan, P. (1996) Developing a Model for Managing Intellectual Capital. European Management Journal 14(4) 356-364.

[17] Zack, M. (1998) Managing Codified Knowledge. Sloan Management Review 40 (4) 45-58.

[18] Ullman, D. (2010) The Mechanical Design Process ( $4^{\text {th }}$ ed). Mc-Graw-Hill. New York NY.

[19] Court, A. (1997) The Relationship Between Information and Personal Knowledge in New Product Development. International Journal of Information Management 17(2) 123-138.

[20] Ramesh, B. \& Tiwana, A. (1999) Supporting collaborative process knowledge management in new product development teams. Decision Support Systems 27 (1-2) 213-235.

[21] Lynn, G.S. \& Akgun, A.E. (2000) A New Product Development Learning Model: Antecedents and Consequences of Declarative and Procedural Knowledge. International Journal of Technology Management 20 490-510.

[22] Kyriakopoulos, K., de Ruyter, K. (2004) Knowledge stocks and information flows in new product development. The Journal of Management Studies 41(8) 1469-1498.

[23] Emden, Z., Calantone, R.J. \& Droge, C. (2006) Collaborating for New Product Development: Selecting the Partner with Maximum Potential to Create Value. Journal of Product Innovation Management 23(4) 330-341.

[24] Benbasat, I., Goldstein, D. \& Mead, M. (1987) The Case Research Strategy in Studies of Information Systems. MIS Quarterly 11(3) 369-386.

[25] Yin, R. (2003) Case study methods: Design and methods. Thousand oaks: SAGE.

[26] Newell, S., Tansley, C. \& Huang, J. (2004) Social Capital and Knowledge Integration in an ERP Project Team: The Importance of Bridging and Bonding. British Journal of Management 15 (1) 43-57.

[27] Enberg, C., Lindkvist, L. \& Tell, F. (2006) Exploring the Dynamics of Knowledge Integration Acting and Interacting in Project Teams. Management Learning 37 (2) 143-165.

[28] Akgün, A., Byrne, J., Keskin, H., Lynn, G., \& Imamoglu, S. (2005) Knowledge networks in new product development projects: A transactive memory perspective. Information \& Management 42(8) 1105-1120.

[29] Vachon, S., \& Klassen, R. (2006). Extending green practices across the supply chain: The impact of upstream and downstream integration. International Journal of Operations \& Production Management 26 (7) $795-821$.

[30] Pfeffer, J., \& Sutton, R. (1999) Knowing 'What' to Do is Not Enough: Turning Knowledge into Action. California Management Review 42 83-108. 
